\title{
Design of inhibitors of leukotriene biosynthesis and their therapeutic potential
}

\author{
Clint D. W. Brooks,* Andrew O. Stewart, Teodozyj Kolasa, Anwer Basha, \\ Pramila Bhatia, James D. Ratajczyk, Richard A. Craig, David Gunn, Richard R. \\ Harris, Jennifer B. Bouska, Peter E. Malo, Randy L. Bell, and George W. Carter

\begin{abstract}
Abbott Laboratories, D-47K, AP10, 100 Abbott Park Road, Abbott Park, Illinois 60064 USA
\end{abstract}

\begin{abstract}
Leukotrienes (LT) are biosynthetic products derived from arachidonic acid. Investigational drugs which inhibit the biosynthesis of LT or block the actions of LT at their receptors have shown therapeutic benefit in asthmatics. A new series of 2-quinolylmethoxyphenylalkyliminoxyalkylcarboxylates was discovered which blocked LT biosynthesis in intact cells but did not inhibit 5-LO catalysis. The mechanism of LT inhibition likely resulted from interfering with five-lipoxygenase activating protein (FLAP). The spatial arrangement and stereochemistry of groups proved important for inhibitory activity. A-93178.5 is an optimized leukotriene inhibitor with potent oral activity in several animal models.
\end{abstract}

Leukotrienes (LT) are biosynthetic products derived from arachidonic acid (AA).(ref. 1) AA is released from esterified phopholipids in response to receptor mediated intracellular influx of $\mathrm{Ca}^{+2}$. Five lipoxygenase activating protein (FLAP) is proposed to act as a carrier protein which presents AA to the 5lipoxygenase (5-LO) enzyme resulting in activation of oxidative catalysis.(ref. 2) 5-LO catalyses two transformations, the addition of molecular oxygen to provide the 5-hydroperoxide intermediate (5-HETE) which is subsequently dehydrated to the reactive epoxide LTA 4 . Two distinct pathways of LTA 4 metabolism provide the other leukotrienes as shown in Figure 1. LTB $_{4}$ has potent activity as a proinflammatory mediator involved in inflammatory cell recruitment, leukocyte activation and adherence of myeloid cells. The cysteinyl LT are very potent mediators of airway smooth muscle contraction, vascular permeability and airway mucus secretion. Studies of the properties and function of LT since their discovery clearly indicated them to be naturally occurring mediators of pathophysiology associated with the symptoms of asthma.(ref. 3) Asthma afflicts over 13 million people in the United States and the incidence, morbidity and mortality has been increasing which points to the fact that current therapy is inadequate. The primary symptoms of asthma are characterized by episodic reversible airway constriction, airway hyperresponsiveness to various stimuli and chronic inflammation.

Research to define appropriate investigational drugs to clearly establish the role of leukotrienes in asthma has proven to be very challenging.(ref. 4) At this time, several agents have progressed through clinical trials and the results confirm that blocking the effects of LT results in a significant therapeutic benefit. Two therapeutic approaches have been successful: inhibiting the biosynthesis of LT and blocking the action of leukotrienes at their respective receptors. LT therapy in asthma has demonstrated immediate airway improvement as a result of preventing the actions of ongoing LT pathology. The degree of improvement in chronic asthmatics was comparable to established therapies which are mechanistically different. The airway improvement was additive with combined treatment with beta-agonists or inhaled steroids. Reduced use of beta-agonists and inhaled steroids was another benefit observed. Anti-LT therapy provides the first mechanistically new therapy for asthma in over twenty years. It remains to be determined whether a specific mode of LT intervention: 5-LO inhibitors, FLAP inhibitors, $\mathrm{LTD}_{4}$ receptor antagonists or $\mathrm{LTB}_{4}$ antagonists will provide distinguishable therapeutic properties. In addition, evaluation of anti-LT drugs in other disorders with LT involvement such as inflammatory bowel disease, rheumatoid arthritis and chronic rhinitis will likely follow. The chronic safety for specific classes of anti-LT drugs over longer periods of therapy also remains to be established. 


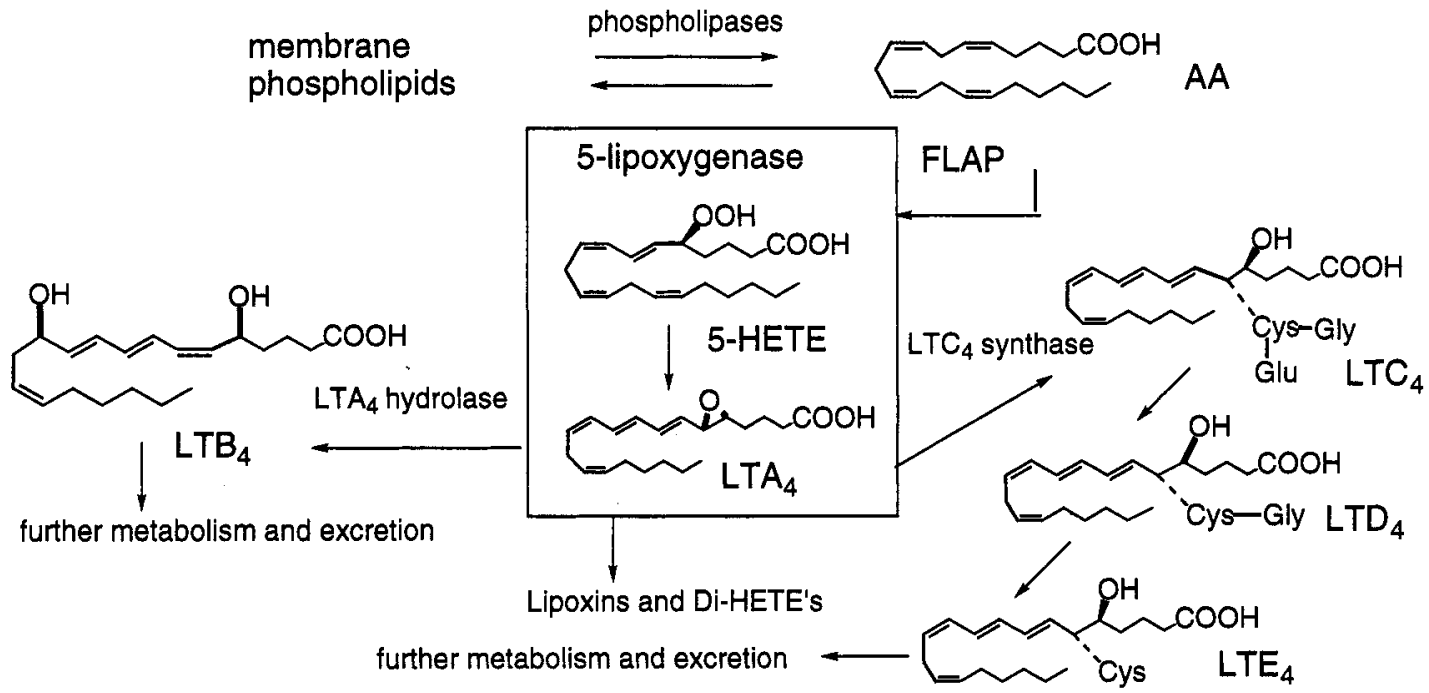

Figure 1. Leukotriene Biosynthesis

Our research focussed on the invention of 5-LO inhibitors. One design hypothesis was to devise a pharmacophore that would bind the $\mathrm{Fe}^{+3}$ atom in the active site of 5-LO and thus block oxidative catalysis. Corey and coworkers first reported hydroxamate containing lipophilic compounds which effectvely inhibited 5-LO in vitro.(ref. 5) We attempted to optimize hydroxamates as potential anti-leukotriene drugs but their propensity for in vivo hydrolysis to inactive carboxylates precluded success for this approach.(ref. 6) We discovered that the $N$-hytdroxyurea provided a more effective pharmacophore with improved in vivo activity. Zileuton became the first 5-LO inhibitor to demonstrate anti-LT activity in man and efficacy in the treatment of asthmatics.(ref. 7) The clinical results with zileuton were promising but revealed a rather short oral half-life of about 3 hours which led to a dosing regime of $600 \mathrm{mg}$ four times a day. The major route of metabolism of zileuton was rapid glucuronidation in the liver followed by urinary excretion. Similar metabolism was found in the cynomolgus monkey. The challenge to devise second generation 5-LO inhibitors involved optimization of inhibitory potency and reducing glucuronidation.

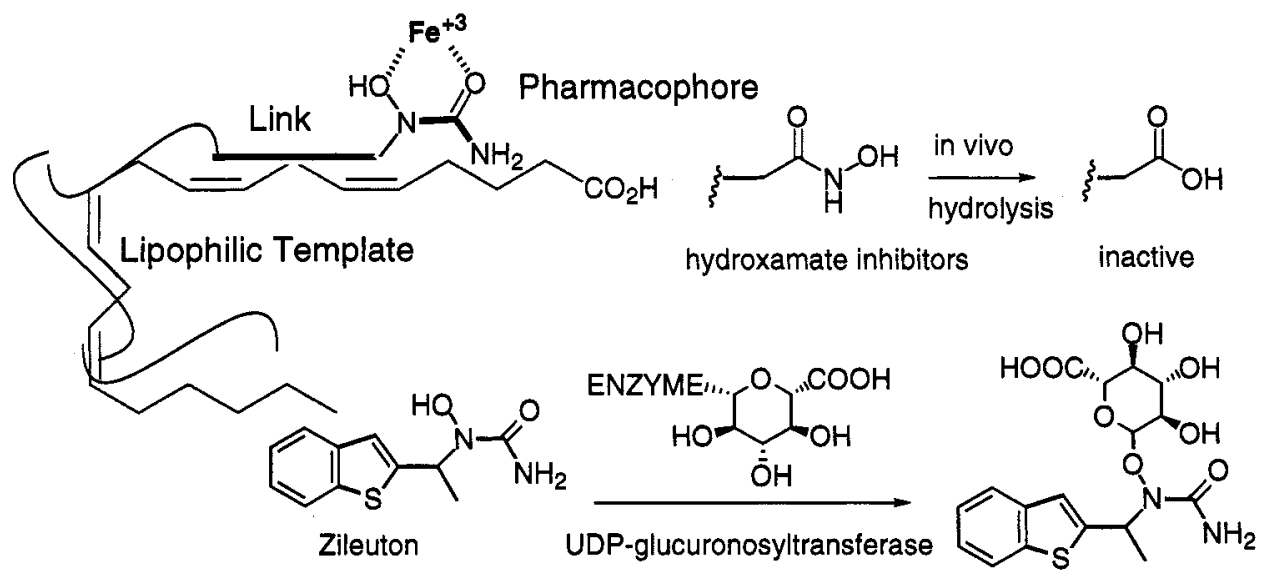

Figure 2. Design of 5-LO Inhibitors from Lipophilic Hydroxamates to Lipophilic $\mathrm{N}$-Hydroxyureas

Extensive structure activity studies were conducted to optimize inhibitory potency and reduced glucuronidation rates in parallel. In vitro assays with liver microsomes from human and monkey were used to measure glucuronidation rates of test compounds in search of structural modifications that resulted in slower rates. A general trend was observed where more lipophilic compounds had greater 5-LO inhibitory activity but also suffered increased glucuronidation rates resulting in poor in vivo duration of inhibition. A breakthrough from this dichotomy was found with analogs containing the butynyl- $N$-hydroxyurea group as in A-79175. Further optimization provided ABT-761 which proved to have a long oral half-life in both humans and monkeys as predicted by the in vitro glucuronidation assays. A single oral dose of $200 \mathrm{mg}$ of 
ABT-761 in humans provided $>95 \%$ inhibition of ex vivo stimulated $\mathrm{LTB}_{4}$ formation in blood samples taken at intervals up to 18 hours postdose and maintained drug concentrations in plasma of $>1 \mu \mathrm{g} / \mathrm{mL}$ for up to 24 hours postdose.(ref. 8)

Table 1. Structural Modifications Resulting in 5-LO Inhibitors with Improved Duration

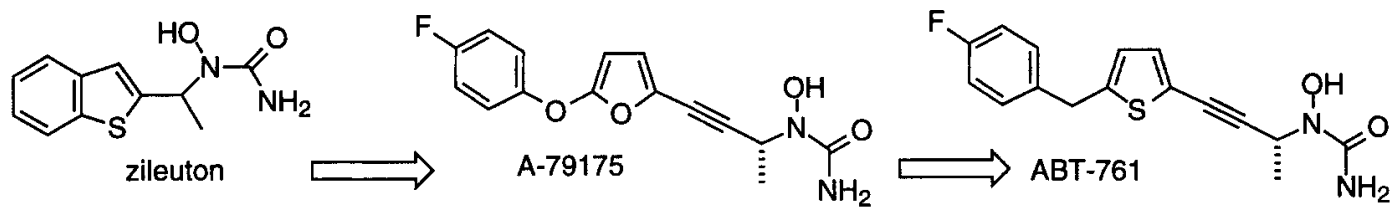

\begin{tabular}{llcccc}
\hline $\begin{array}{l}\text { Compound } \\
\text { (concentration) }\end{array}$ & \multicolumn{2}{c}{$\begin{array}{c}\text { Rate of Glucuronidation a } \\
\text { Monkey }\end{array}$} & Human & \multicolumn{2}{c}{ Half life (hours) } \\
Monkey (iv) & Human (oral) \\
\hline & & & & & \\
zileuton & $(100 \mu \mathrm{M})$ & 0.120 & 0.290 & 0.4 & 2.3 \\
A-79175 & $(500 \mu \mathrm{M})$ & 0.025 & 0.040 & 8.7 & 7.0 \\
ABT-761 & $(500 \mu \mathrm{M})$ & 0.000 & 0.005 & 16 & 15 \\
\hline
\end{tabular}

a liver microsome preparations, rate of glucuronidation is expressed as nmole $/ \mathrm{min} / \mathrm{mg}$ protein

With the optimization of the $\mathrm{N}$-hydroxyurea class of 5-LO inhibitors completed, we turned our attention to creating a new class of FLAP inhibitors. Merck Frosst researchers had discovered FLAP and invented several potent FLAP inhibitors such as MK-0591.(ref. 9) Two other compounds, the venerable reference standard leukotriene inhibitor REV-5901 (ref. 10) and BAY X1005 (ref. 11) were interesting leads. The quinolylmethoxyphenyl group had become a recognized pharmacophore for LT inhibitory or receptor antagonist activity.(ref. 12) We attempted to create a new class of FLAP inhibitors with improved in vivo inhibitory activity by application of our oxime insertion theory. Our hypothesis derives from the following assumptions: that the oxime function can be inserted into an alkyl or alkenyl chain to provide improved in vivo properties by restricting the spatial orientation of binding groups and the oxime function can be inserted in one of several orientations to provide additional hydrogen bonding interactions. In addition, the oxime heteroatoms improve solubilization/absorption phenomena over their alkyl counterparts. Most important this concept provides synthetic access to greater diversity of composition by application of combinatorial chemistry methods. This theory is outlined in Figure 3.

\section{Oxime Insertion}

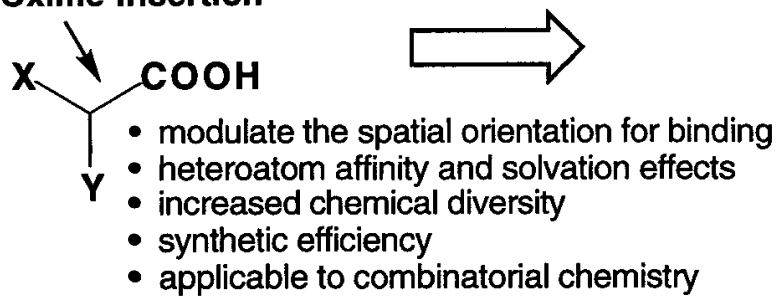

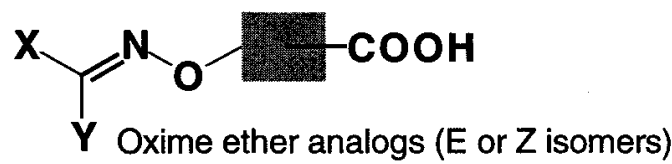

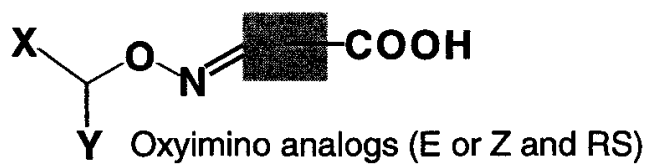

Figure 3. Oxime Insertion Theory for Creating Analogs with Improved In Vivo Activity

Applying the oxime insertion theory inspired the synthesis and evaluation of three oxime isomers: A-86197, A-93175 and A-93176. The LT inhibitory activity of the oxyiminocarboxylate analog, A-93176 with the Eoxime geometry was about 2-fold more potent than BAY X-1005. The spatial arrangement and stereochemistry of groups proved important for inhibitory activity. Methods to resolve racemic A-93176 were developed that provided the (S +)-E-isomer, A-93178 which proved to be more potent than the (R -) enantiomer, A-93177. A-93178.5 (sodium salt form) was selected for further study and its properties were compared to reference leukotriene inhibitors as shown in Table 2. 


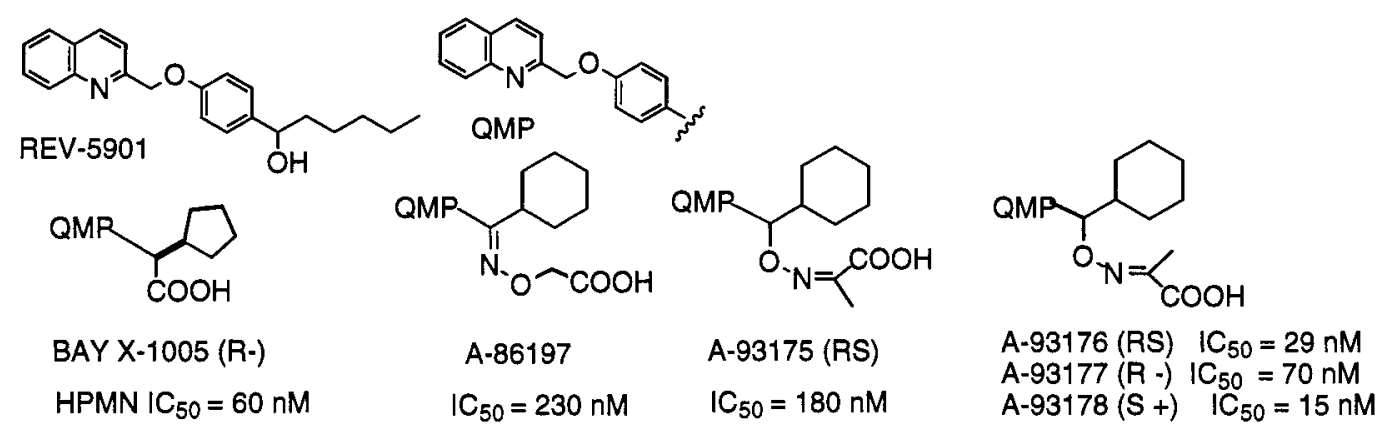

Table 2. Comparison of Biological Activity of LT Inhibitors

\begin{tabular}{|c|c|c|c|c|}
\hline Method & A-93178.5 & ABT-761 & zileuton & BAY X-1005 \\
\hline human neutrophil (HPMN) (IC 50$)$ & $34 \mathrm{nM}$ & $23 \mathrm{nM}$ & $320 \mathrm{nM}$ & $60 \mathrm{nM}$ \\
\hline RBL-1 sonicate $\left(\mathrm{IC}_{50}\right)$ & inactive & $50 \mathrm{nM}$ & $92 \mathrm{nM}$ & inactive \\
\hline human whole blood $\left(\mathrm{IC}_{50}\right)$ & $870 \mathrm{nM}$ & $150 \mathrm{nM}$ & $740 \mathrm{nM}$ & $6,000 \mathrm{nM}$ \\
\hline $\begin{array}{l}\text { rat anaphylaxis (oral } \mathrm{ED}_{50} \text { ) } \\
\text { rat lung eosinophilia (oral } \mathrm{ED}_{50} \text { ) }\end{array}$ & $0.4 \mathrm{mg} / \mathrm{kg}$ & $1.0 \mathrm{mg} / \mathrm{kg}$ & $6 \mathrm{mg} / \mathrm{kg}$ & $4 \mathrm{mg} / \mathrm{kg}$ \\
\hline $\mathrm{LTE}_{4}$ in $\mathrm{BAL}$ & $0.1 \mathrm{mg} / \mathrm{kg}$ & $1.6 \mathrm{mg} / \mathrm{kg}$ & $8.5 \mathrm{mg} / \mathrm{kg}$ & $50 \% \mathrm{I}$ at $10 \mathrm{mg} / \mathrm{kg}$ \\
\hline eosinophil influx in BAL & $0.2 \mathrm{mg} / \mathrm{kg}$ & $1.4 \mathrm{mg} / \mathrm{kg}$ & $10 \mathrm{mg} / \mathrm{kg}$ & $50 \%$ I at $10 \mathrm{mg} / \mathrm{kg}$ \\
\hline guinea pig bronchospasm (oral $\mathrm{ED}_{50}$ ) & $2 \mathrm{mg} / \mathrm{kg}$ & $4 \mathrm{mg} / \mathrm{kg}$ & $12 \mathrm{mg} / \mathrm{kg}$ & $79 \%$ I at $10 \mathrm{mg} / \mathrm{kg}$ \\
\hline
\end{tabular}

The inhibitory activity of A-93178.5 was comparable to ABT-761 in the intact human neutrophil but less in human whole blood due to greater plasma protein binding affinity. A-93178.5 did not inhibit the 5-LO activity in the RBL-1 broken cell assay as expected for a FLAP inhibitory mechanism. Superior activity was found for A-93178.5 in several in vivo models of leukotriene pharmacology. In the rat A-93178.5 was $>10$-fold more potent than zileuton and BAY X-1005 in blocking LT formation in a passive anaphylaxis reaction. In a model of lung inflammation, Brown Norway rats injected with Sephadex G200 develop increased levels of cysteinyl LT and eosinophils in bronchoalveolar lavage fluid (BAL). A-93178.5 had an oral $\mathrm{ED}_{50}$ of $0.1 \mathrm{mg} / \mathrm{kg}$ for blocking $\mathrm{LTE}_{4}$ in $\mathrm{BAL}$ and an $\mathrm{ED}_{50}$ of $0.2 \mathrm{mg} / \mathrm{kg}$ for blocking eosinophil influx in BAL. In a guinea pig model of airway obstruction, A-93178 was very effective with an oral $\mathrm{ED}_{50}$ of 2 $\mathrm{mg} / \mathrm{kg}$. The oxime ether insertion theory proved to be an effective strategy for the invention of novel LT inhibitors with excellent in vivo pharmacological properties. A-93178.5 represents an optimized LT inhibitor with properties comparable or superior to the current anti-leukotriene clinical candidates.

\section{REFERENCES}

1. B. Samuelsson. Science 220, 568 (1983).

2. M Abramovitz, E. Wong, M.E. Cos, C.D. Richardson, C. Li, and P. J. Vickers. Eur. J. Biochem. 215, 105 (1993).

3. E. Israel. Ann. Allergy 72, 279 (1994).

4. C. D. W. Brooks and J. B. Summers. J. Med. Chem. 39, 2629 (1996).

5. E. J. Corey, J. R. Cashman, S. S. Kanter, and D. R. Corey. J. Am. Chem. Soc. 106, 1503 (1984).

6. J. B. Summers, B. P. Gunn, H. Mazdiyasni, A. M. Goetze, P. R.Young,.J. B. Bouska, R. D. Dyer, D. W. Brooks, and G. W. Carter. J. Med. Chem. 30, 2121 (1987).

7. D. W. Brooks and G. W. Carter. In The Search for Anti-inflammatory Drugs (V. J. Merluzzi and J. Adams, ed.), pp 129-160, Birkhauser, Boston (1995).

8. C. D. W. Brooks, A. O. Stewart, A. Basha, P. Bhatia, J. D. Ratajczyk, J. G. Martin, R. A. Craig, T. Kolasa, J. B. Bouska, C. Lanni, R. R. Harris, P. E. Malo, G. W. Carter, and R. L. Bell. J. Med. Chem. 38, 4768 (1995).

9. P. Prasit and P. J.Vickers. In The Search for Anti-inflammatory Drugs (V. J. Merluzzi and J. Adams, ed.), pp 233-251, Birkhauser, Boston (1995).

10. J. H. Musser, U. Chakraborty, S. Sciortino, R. J. Gordon, A. Khandwala, E. S. Neiss, R. P. Pruss, R. Van Inwegen, I. Weinryb, and S. M. Coutts. J. Med. Chem. 30, 96 (1987).

11. A. Hatzelmann, R. Fruchtmann, K.-H. Mohrs, S. Raddatz, R. Müller-Peddinghaus. Biochem. Pharm. 45, 101 (1993).

12. J. H. Musser and A. F. Kreft. J. Med. Chem. 35, 2502 (1992). 